\title{
Origens e afiliações epistemológicas da Teoria Ator-Rede: implicações para a análise organizacional
}

\author{
DANY FLÁVIO TONELLI \\ Universidade Federal de LaVras / Departamento de Administração e EConomia, Programa de Pós-graduação em \\ AdMINISTRAÇÃO PÚBLICA, LAVRAS - MG, BRASIL
}

\begin{abstract}
Resumo
O objetivo deste artigo é apresentar algumas origens e influências epistemológicas que moldaram a Teoria Ator-Rede (TAR), visando a contribuir para sua inserção esclarecida no contexto da análise organizacional. Depois da apresentação inicial e de uma reflexão sobre as origens da TAR, são discutidos os seguintes temas: i) crítica da "construção social da realidade"; ii) conceito de "simetria"; iii) conceito de "translação"; e iv) expansão do significado de "atuante". Ao final são exploradas as implicações para a análise organizacional, as quais reforçam a importância dos conceitos básicos para a compreensão da TAR, colaborando para a sedimentação do uso de suas categorias em diversos campos científicos.
\end{abstract}

Palavras-chave: Sociologia do conhecimento. Simetria. Translação. Atuante. Análise organizacional.

Epistemological origins and affiliations of the Actor-Network Theory: implications for organizational analysis

\section{Abstract}

This article aims to introduce some epistemological origins and influences that shaped the Actor-Network Theory (ANT), in order to contribute to its informed insertion in the context of organizational analysis. After the initial presentation and a reflection on the origins of the ANT, the following themes are discussed: i) critique of the "social construction of reality;" ii) concept of "symmetry;" iii) concept of "translation;" and iv) expanded meaning of "actant." In the end, implications for organizational analysis are explored, which reinforce the importance of primary concepts for grasping the ANT, contributing to establish the use of its main categories in various scientific fields.

Keywords: Knowledge sociology. Symmetry. Translation. Actant. Organizational analysis.

\section{Orígenes y afiliaciones epistemológicas de la Teoría Actor-Red: implicaciones para el análisis organizativo}

\section{Resumen}

El propósito de este artículo es presentar algunas orígenes e influencias epistemológicas que han dado forma al Teoría del Actor-Red (TAR), con el objetivo de contribuir a su inserción clarificada en el contexto del análisis organizativo. Después de la presentación inicial y una reflexión sobre las orígenes de la TAR, se tratan los siguientes temas: i) crítica de la "construcción social de la realidad"; ii) concepto de "simetría"; iii) concepto de "traslación"; y iv) ampliación del significado de "actuante". Al final hemos explorado las implicaciones para el análisis organizativo, que refuerzan la importancia de los conceptos básicos para entender la TAR, que contribuye a la consolidación de la utilización de sus categorías en diversos campos científicos.

Palabras clave: Sociología del conocimiento. Simetría. Traslación. Actuante. Análisis organizativo. 


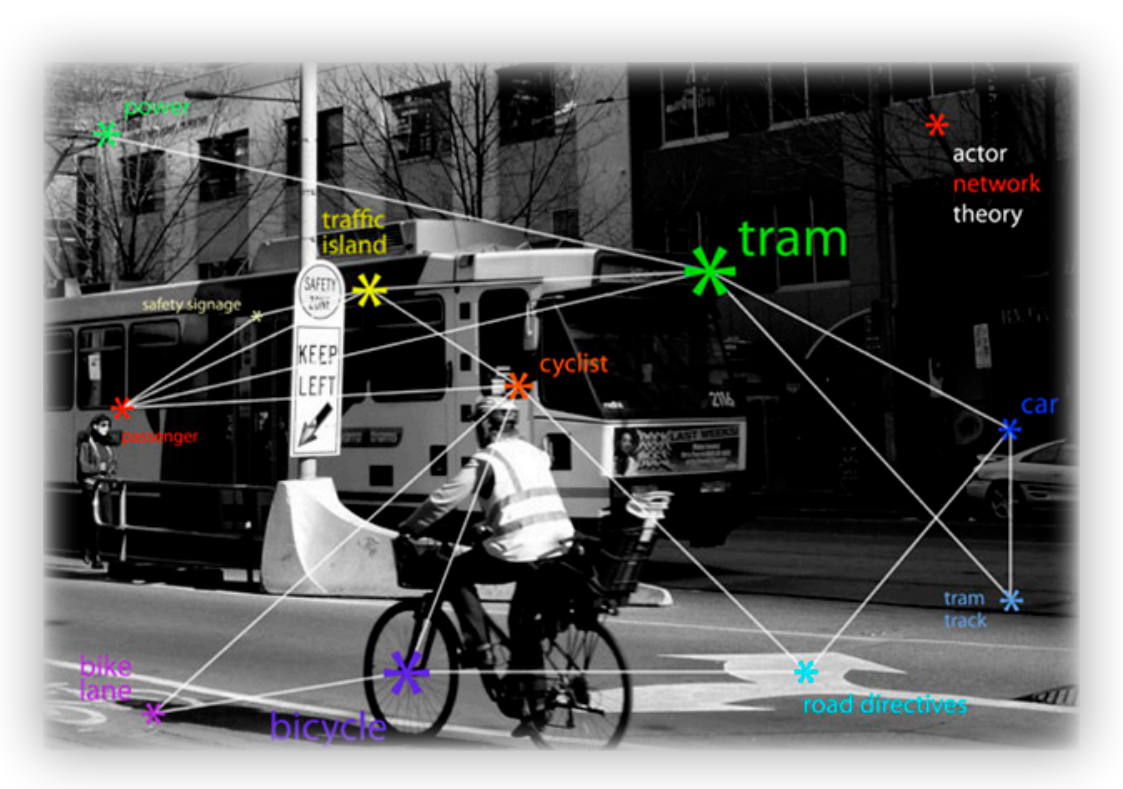

\section{INTRODUÇÃO}

A Teoria Ator-Rede (TAR) tem influenciado direta ou indiretamente análises em diversas áreas do conhecimento, como educação (QUEIROZ e MELO, 2011), ciência da informação (ODDONE, 2007), psicologia (TSALLIS et al., 2006), comunicação (SILVA, 2011), sociologia (MUÑOZ, PABLOS, VÁZQUEZ et al., 2005; MURIEL, 2011), geografia (PRYTHERCH, 2011) e direito (COWAN e CARR, 2008).

Sobre os estudos organizacionais, uma importante contribuição da TAR diz respeito ao redirecionamento do foco de análise para o processo de organização (organizing) e seus variados aspectos de interesse, como tecnologia, mudança organizacional, rotinas, organização virtual, poder, mecanismos de mercado e gestão do conhecimento, entre outros (CZARNIAWSKA e HERNES, 2005; ORLIKOWSKI, 2007; ALCADIPANI e HASSARD, 2010). Davenport (2006) afirma que a TAR inverte os pressupostos da corrente tradicional de análise organizacional, assumindo que a existência dos atores não precede a existência das redes em que eles se inserem. Posicionamentos como este, além do vocabulário que lhe é peculiar, possibilitam à TAR oferecer insights novos que podem ampliar a compreensão de como os processos organizativos adquirem certa estabilidade quando inscrevem uma série de entidades formadas simultaneamente de elementos humanos e não humanos.

Entretanto, quanto maior o espaço ocupado pela TAR, maior é o número de críticas que ela recebe. Baseado no pós-estruturalismo marxista de Deleuze e Guattari, Roberts (2012), por exemplo, afirma que a TAR (considerada outra vertente do pós-estruturalismo) direciona sua atenção para os aspectos concretos e contingentes das organizações, não dando importância à sua forma abstrata, o que faz que as contradições do capitalismo em sua essência sejam ignoradas, pois reproduzem dualismos em uma variedade de formas.

Seja produzindo consenso ou provocando controvérsia, não se pode negar a crescente influência da TAR. Nota-se isso por meio do crescente interesse de estudiosos sobre o tema. No Brasil, por exemplo, diversos estudos estão adotando essa perspectiva (veja-se, por exemplo, ALCADIPANI e TURETA, 2009; TONELLI, BRITO e ZAMBALDE, 2011; TELES e JOIA, 2012; CAVALCANTI e ALCADIPANI, 2013; e MONTENEGRO e BULGACOV, 2015). Contudo, alguns aspectos demandam mais aprofundamento e ilustram um gap de pesquisa ainda pouco explorado. Esses dizem respeito a questões de natureza fundamental como: Quais são as influências exercidas pela sociologia do conhecimento e pela filosofia da ciência por meio de conceitos como o de "simetria" originário de Bloor (1976) e o de "translação" originário de Serres (1990)? Como a compreensão desses conceitos na sua origem pode contribuir para o uso da TAR nos estudos organizacionais?

\footnotetext{
* Fonte da imagem: Disponível em <http://www.designpracticemethods.rmit.edu.au/systematic-methods/actor-network-theory/ > Acesso em 14 mar. 2016
} 
Para oferecer um esforço de aprofundamento do debate, o objetivo é apresentar algumas das origens e influências epistemológicas que moldaram a TAR, visando a contribuir para sua inserção, de modo esclarecido, no contexto da análise organizacional. Acredita-se que muitos iniciantes ou até mesmo praticantes da TAR possam encontrar dificuldades de natureza epistemológica. Por esse motivo, o esforço de sintetizar argumentos complexos e oferecer um referencial de estudos, assim como propor novos debates em um movimento reflexivo pode ser útil. Para tanto, foi feita uma revisão da literatura especializada. De início, são apresentados conceitos introdutórios que possibilitam ao leitor uma noção geral acerca do que é a TAR e de quais são algumas de suas proposições. Em seguida apresenta-se uma história da sua origem nos Estudos de Ciência e Tecnologia (ECT) e da forma como se distinguiu em relação a outras abordagens de estudo das relações e interações sociotécnicas. Depois são explorados conceitos que aproximam e distanciam a abordagem de outras, como: i) a noção de "construção social da realidade"; ii) o conceito de Simetria originário do "programa forte de sociologia do conhecimento" de David Bloor; iii) o conceito de "translação" cunhado por Michel Serres a fim de representar o tempo como o espaço da simultaneidade; e iv) a expansão do significado de atuante para além da atuação apenas das pessoas. No último tópico são apresentadas algumas considerações e implicações para a pesquisa e a análise organizacional.

\section{CONCEITOS INICIAIS}

A TAR foi elaborada e desenvolvida principalmente por três autores: Bruno Latour, Michel Callon e John Law. Desses autores podemos extrair três aspectos que distinguem a TAR das demais correntes teóricas. O primeiro diz respeito à rejeição aos dualismos por meio da introdução de um novo tratado semiótico (LAW, 1999; 2003; LATOUR, 2001; 2005b). Para LaW (1999), essa característica se manifesta na busca de superação das divisões entre, por exemplo, agência e estrutura, micro e macro, antes e depois, humano e não humano, conteúdo e contexto e materialidade e sociedade.

O segundo aspecto está no fato de a TAR investir no método de seguir os atores e as ações para dar conta da realidade (CALLON, 1986; LATOUR e WOOLGAR, 1997; LATOUR, 1996). Conforme Latour (1999), não se trata de fazer como as ciências sociais habitualmente fazem, buscando em elementos da sociedade (como normas, cultura e valores) os motivos para compreender os espaços das microinterações. Quando esse espaço é alcançado, percebe-se que ainda falta alguma coisa, uma vez que normas, cultura e valores parecem conceitos muito amplos para dar pleno significado ao micro. Faz-se então o caminho inverso, na esperança de preencher as lacunas e, assim, perpetuam-se as limitações das ciências sociais. O método proposto concentra seu foco em desnudar as interações e as associações que se estabelecem por meio de diversos tipos de elementos heterogêneos dentro de um lócus mais restrito.

O terceiro aspecto está no fato de não se definir a priori o que é um ator ou quais elementos fundamentais ele deve reunir (LATOUR, 1996; CALLON, 1999; LATOUR, 2005b). Callon (1999) afirma que, embora seja um aspecto muito criticado, também representa uma das maiores forças da TAR, o que lhe permite representar uma variedade de possibilidades de ações e de atores. A identidade dos atores e das ações depende de suas configurações. Uma vez que a ação e os atores não são apenas humanos, mas simultaneamente não humanos, permanecem abertas as possibilidades de identidades e de configurações.

Chama a atenção na expressão "Teoria Ator-Rede" o hífen que liga os termos ator e rede. Esse hífen revela o propósito de representá-los como uma única entidade (LATOUR, 1990). Não pode existir ator sem que haja rede. O ator só é ator porque ele adquire forma, significado e identidade na rede. O que explica a realidade não é unicamente o ator, nem unicamente a rede em que ele se insere. Há aí uma preocupação em enfatizar uma conexão indispensável (GEELS, 2005). Segundo Law (1999), "ator-rede" apresenta um oximoro semiótico proposital que pretende combinar e eliminar a distinção entre agência e estrutura. A realidade não se explica apenas por meio de uma combinação de elementos vindos das esferas subjetiva e objetiva. Os elementos que produzem a realidade trazem consigo ambas as esferas de modo inseparável. Qualquer ator-rede não poderia ser compreendido se fosse possível tão só dissociar dele o subjetivo ou o objetivo.

Uma vez que todas as entidades são resultantes de suas relações com outras entidades não há sentido em aceitar a ideia imposta pelas fronteiras das metáforas dualistas (LAW, 1999). Law (1999, p. 3) afirma que:

[...] entidades são formadas e estabelecem suas relações com outras entidades. Nesse esquema de coisas, entidades não têm qualidades inerentes: divisões essencialistas são jogadas nas fogueiras dos dualismos. [...]. De uma ou outra forma, todas as 
divisões são refutadas no trabalho realizado em nome da Teoria Ator-Rede (tradução nossa). Uma preocupação fundamental da TAR é ir além dos significados dados, dos pressupostos semânticos da linguagem teórica tradicional. Para lidar com tais dilemas seria necessário um novo acordo semântico. Um novo sistema linguístico permitiria atribuições de sentido menos influenciadas pela tradição sociológica, o que ocupou um espaço importante na discussão entre os estudiosos. Em Latour (1999) é possível perceber essa preocupação, decorrente da opção de não se restringir em meio aos limites cognitivos impostos por dilemas intermináveis. Ao discutir algumas das categorias-chave será possível abordar um pouco da origem desses novos significados.

\section{OS ESTUDOS EM CIÊNCIA E TECNOLOGIA}

Embora presente como orientação metodológica em diversos campos do conhecimento, a TAR nasceu como um ramo dos ECT, área de pesquisas que se desenvolveu em torno do debate sobre onde, como e se é possível estabelecer limites entre sociedade e tecnologias (BIJKER e LAW, 1992). Os ECT se contrapõem à noção predominante de que ciência e tecnologia sejam produzidas por meios puramente racionais. No senso comum, o ato de produzir ciência ou tecnologia é considerado atividade isenta de influências sociais ou culturais. Ao contrário disso, a verdade científica não está alheia às controvérsias humanas (HESS, 1995). Entretanto, os ECT representam um corpo teórico que abriga visões idiossincráticas e divergentes entre si. Estudiosos do campo (HUGHES, 1986; BIJKER e LAW, 1992; BIJKER, 1995) destacam pelo menos duas abordagens distintas, cada qual entendendo diferentemente o relacionamento entre tecnologia e sociedade. A primeira pode ser chamada de interativa e a segunda, de "teia sem costuras" (seamless web).

A abordagem interativa tem três características essenciais: i) considera uma divisão entre o social e o técnico; ii) considera que o social molda o técnico; e iii) aceita a possibilidade recíproca de o técnico também ser capaz de moldar o social. Ela rejeita quaisquer reducionismos oriundos tanto do determinismo social quanto do determinismo tecnológico, argumentando que há certa relação de troca e interação que impede a submissão unilateral de um pelo outro (BIJKER e LAW, 1992).

A visão interativa é decorrente de certa resistência no âmbito de estudos históricos da ciência e da tecnologia a partir da década de 1970. Ela se dá em relação à noção internalista de história científica e tecnológica predominante até então na comunidade científica e entre os filósofos da ciência (entre eles, destaca-se Imre Lakatos e sua tese dos programas de pesquisa ${ }^{2}$ ). Os internalistas defendiam que o entendimento acerca do desenvolvimento da ciência ou da tecnologia dependia unicamente do entendimento dos aspectos intrínsecos da ciência ou da tecnologia em si. Os externalistas alegavam que as contingências do contexto político, social, econômico e científico são tão importantes para o desenvolvimento da ciência e da tecnologia quanto as características endógenas (BIJKER, 1995).

Paralelamente a esse debate havia outro ocorrendo entre, de um lado, historiadores da ciência e, de outro, historiadores da tecnologia. Estes não aceitavam a inserção da tecnologia no contexto das ciências, pois acreditavam que havia uma interação entre ciência e tecnologia, mas não uma dependência contextual (HUGHES, 1986). Essa posição acabou sendo uma grande limitação imposta pelos interativistas a si próprios, fazendo surgir o movimento apelidado de "teia sem costuras" (TSC), que buscou o rompimento com a noção de interação apenas entre ciência e tecnologia. A visão TSC abre possibilidades para o contexto das relações que se estabelecem em meio a uma série de atores e instituições (HUGHES, 1986).

A visão mais radical da TSC não admite divisões estáveis entre o social e o técnico. A análise da realidade social deveria começar com a reconstrução analítica de uma teia. A reconstrução seria sempre parcial, uma vez que é impossível ao analista visualizar todas as relações e os elementos constituintes da teia. Embora parcial, apenas por meio da reconstrução é possível

\footnotetext{
${ }^{2}$ A metodologia dos programas de pesquisa de Lakatos considera a ciência não como um todo, mas, sim, como programas particulares de pesquisa, como o conhecido por "metafísica cartesiana". Os programas têm um núcleo em torno do qual impera a necessidade de articular ou mesmo inventar hipóteses auxiliares que formam um cinto de proteção. É esse cinto de proteção que tem de sustentar o impacto dos testes e ir se ajustando e reajustando, ou mesmo ser totalmente substituído conforme a necessidade de fortalecimento do núcleo. "O programa de pesquisa será bem-sucedido se tudo isso conduzir a uma transferência progressiva de problemas, porém malsucedido se conduzir uma transferência degenerativa de problemas" (LAKATOS, 1979, p. 163). A grande crítica dos interativistas a Lakatos (1979) estava centrada na recusa dele em reconhecer que os aspectos extracientíficos são essenciais para compreender a consolidação de qualquer disciplina científica.
} 
avaliar como a realidade é afetada por diferentes tipos de circunstâncias, as quais permitem a criação de diferentes tipos de objetos e propósitos (BIJKER e LAW, 1992).

Na visão da TSC se inserem as abordagens da estrutura tecnológica (technology frame) e da TAR. Uma característica comum e marcante dessas duas abordagens está no fato de considerarem o social e o técnico como criados, percebidos e compreendidos por meio do movimento, da ação (BIJKER, 1995).

O conceito de estrutura tecnológica (technology frame) (BIJKER, 1995) é análogo ao conceito de estruturação (GIDDENS, 1989), no qual a estrutura é vista como produtora e produto da ação dos agentes cognoscíveis. Esses agentes estão sujeitos à sua estrutura social e, ao mesmo tempo, são fundamentos sobre os quais essa se constrói. Entretanto, a estrutura tecnológica de Bijker (1995) difere da estrutura social de Giddens (1989), uma vez que esta última não faz referência a formas de ação coletiva, como as que ocorrem em organizações, colocando um foco incômodo sobre uma agência humana irredutível (BIJKER, 1995).

A estrutura tecnológica funciona de modo similar aos paradigmas (KUHN, 2006), quando esses são usados para explicar a estabilidade da ciência normal. Entretanto, a proposta embute incentivos para a mudança, mudança esta que irá depender do grau de inclusão de um agente de mudança em uma estrutura tecnológica vigente. Como exemplo, Bijker (1995) apresenta um estudo detalhado do surgimento (construção social) do plástico. O inventor do primeiro material plástico sintético, em 1907, Leo Baekeland, foi o resultado de sua inserção tanto na estrutura tecnológica da celulose quanto parcialmente na estrutura tecnológica da eletroquímica. $\mathrm{O}$ acesso a essas duas estruturas tecnológicas possibilitou a Baekeland se tornar um agente de mudança. Bijker (1995) deixa claro, por meio desse e de outros exemplos, que a estrutura tecnológica é externa aos indivíduos, ainda que localizada no nível de um grupo social relevante. As estruturas tecnológicas não seriam entidades fixas, mas construídas, em parte, por meio do processo de estabilização de um artefato orientado continuamente por ações e interações. A esse respeito, Bijker (1995, p. 193) exemplifica: “A construção social de um artefato (exemplo: celuloide), a formação de um grupo social relevante (exemplo: engenheiros de celuloide) e a emergência de um enquadramento tecnológico (exemplo: enquadramento do celuloide) são processos interligados". (tradução nossa).

A mesma ideia de que a realidade é percebida como produto da interação entre diversos elementos distintos está presente na TAR. Entretanto, duas características a distinguem. A primeira tem a ver com a preocupação em introduzir uma linguagem distinta daquela que poderia naturalizar percepções polarizadas da realidade. A segunda está na preocupação em tornar simétrica a agência dos não humanos em relação à agência das pessoas, impondo, assim, o mesmo estatuto ontológico a essas duas categorias de agentes até então consideradas distintas (AKRICH e LATOUR, 1992). A simetria humano-não humano favorece uma concepção distintiva de realidade. Nisso há outra ruptura importante produzida pela TAR, dessa vez com a abordagem da construção social da realidade.

\section{LIMITES DO CONSTRUTIVISMO SOCIAL}

Há décadas, a abordagem da construção social da realidade (BERGER e LUCKMAN, 2008) vem influenciando diferentes áreas do conhecimento (YOUNG e COLLIN, 2004; CAMARGO-BORGES e RASERA, 2013). Nos estudos organizacionais, entre outras contribuições, essa abordagem desempenha o papel de contraposição ao funcionalismo e ao positivismo modernistas por meio da busca por maior problematização de pressuposições socialmente construídas nas organizações e que dizem respeito, por exemplo, à agência racional, ao conhecimento empírico e às formas de linguagem e de representação (GERGEN e THATCHENKERY, 2004).

Em se tratando dos estudos sociais em ciência e tecnologia, conforme Hagendijk (1990), o construtivismo contribuiu para consolidar duas visões distintivas. A primeira diz respeito ao entendimento de que o conhecimento científico é construído ao invés de descritivo de uma natureza externa. Assim, os fatos científicos são criados pelos cientistas e deveriam ser analisados com base nessa compreensão. A segunda pressupõe que a estrutura social é a consequência e não a causa do que as pessoas fazem. Com isso, o construtivismo impõe distanciamento marcante dos esforços prévios de desenvolvimento de uma visão sociológica das ciências (HAGENDIJK, 1990). De modo geral, para os construtivistas sociais, todo o conhecimento reside na mente das pessoas. Eles se preocupam em entender "como as facticidades objetivas" se tornam "significados subjetivos" 
(PECl e ALCADIPANI, 2006, p. 147). Isso conduz ao entendimento, conforme Michael (1996), que do ponto de vista ontológico a realidade seria o resultado da cognição humana.

Na análise de Hacking (1999) é possível notar que a expressão "construção social" se tornou uma referência recorrente para explicar uma diversidade de assuntos nos debates da política, das relações familiares, de gênero, da cultura, das raças e da ciência. Por exemplo, as mães que aceitam os padrões de emoção e comportamento devem aprender que os caminhos que as conduziram a sentir e agir dessa forma não estão relacionados com a "natureza humana" ou com a "biologia da reprodução", mas são produtos de "eventos históricos", "forças sociais" e "ideologia" (HACKING, 1999, p. 2). De acordo com o autor, há uma espécie de uso demasiado do construtivismo social. Isso simplifica sobremaneira o entendimento sobre o processo de construção da realidade por pesar mais os aspectos subjetivos, tal qual fazem outras abordagens, como a etnometodologia ${ }^{3}$.

Se analisada do espectro da TAR, a concepção de realidade que desconsidera o lado material e objetivo daquela é inaceitável. Considerar o lado não humano é ponto fundamental para se compreender as ações coletivas. Isso provoca um questionamento acerca de alguns dos pressupostos subjacentes da "virada linguística", os quais são tão característicos de boa parte do construtivismo social (MICHAEL, 1996).

Latour critica o discurso da modernidade e o consequente desígnio de separar o objetivo do subjetivo. Desde seu início iluminista, a modernidade buscou purificar a prática científica de qualquer outra atividade, introduzindo, com isso, dicotomias entre, por exemplo, o científico e o não científico e a sociedade e a natureza (LATOUR, 2000; 2001; 2004; 2005b). A respeito disso, o construtivismo social contribuiu para desmistificar a existência de uma ciência neutra e descritiva da verdade exterior. Entretanto, ele manteve a dependência em uma agência humana irredutível (em contraposição a esse pressuposto, veja, por exemplo, Bijker, 1995). Latour (2000), por sua vez, defende o argumento de que as entidades reais são híbridas. É impossível circunscrever ao social o processo de construção da realidade. Ele ocorre simultânea e indissociavelmente com base em elementos humanos e não humanos, discursivos e materiais.

A controvérsia fundamental está no fato de o construtivismo social não considerar problemáticos os não humanos (MICHAEL, 1996). O construtivismo social prioriza o linguístico, tirando do foco as entidades não linguísticas, não humanas e não sociais (em última instância, essas são construções das atividades linguísticas, intersubjetivas e intertextuais). Akrich e Latour (1992) afirmam que o construtivismo social nega a atuação dos objetos, assumindo que apenas as pessoas são capazes de atuar. Portanto, faz-se necessário mudar o quadro de referência do social. Latour (2001) faz uso do recurso da semiótica, oferecendo um termo opcional ao social, o qual não tenha seu significado subvertido tão facilmente como algo oposto à natureza. Trata-se do termo "coletivo"4.

Coletivo é mais amplo do que sociedade, pois enfatiza as associações entre humanos e não humanos: "um intercâmbio de propriedades humanas e não humanas no seio de uma corporação" (LATOUR, 2001, p. 222). Com a adoção do coletivo, isso não significa desconsiderar os traços característicos das diversas partes que o integram. Como afirma Latour (2001, p. 222223, grifo do autor),

[...] o jogo não consiste em estender a subjetividade às coisas, tratar humanos como objetos, tomar máquinas por atores sociais e sim "evitar a todo custo o emprego" da distinção sujeito-objeto ao discorrer sobre o entrelaçamento de humanos e não humanos. O que o novo quadro procura capturar são os movimentos pelos quais um dado coletivo "estende" seu tecido social a "outras" entidades. É isso que eu quis dizer até agora com a expressão provisória Ciência e tecnologia são aquilo que socializa não humanos para que travem relações humanas. Improvisei a seguinte frase para substituir a expressão

\footnotetext{
${ }^{3}$ Campo da sociologia que investiga o funcionamento do conhecimento produzido pelo senso comum e do raciocínio prático em contextos sociais. É o oposto de perspectivas que consideram o comportamento humano produto de estímulos causais externos ou de motivações internas. Foi fundada por Harold Garfinkel, que afirmava que uma teoria da ação e da organização sociais estaria incompleta sem uma análise acerca de como os agentes sociais compartilham conhecimento e raciocínio produzidos pelo senso comum na condução de seus assuntos comuns. A principal inovação está no estabelecimento de explicações das propriedades do conhecimento produzido pelo senso comum, das compreensões compartilhadas e da ação social ordinária que pode ser desenvolvida em um programa de pesquisa empírica (OUTHWAITE e BOTTOMORE, 1996).

${ }^{4}$ Em vez de dinâmicas sociais, o uso de dinâmicas coletivas evita o viés semiótico de, ao enfatizar apenas o termo social, desconsiderar o lado não social dessas dinâmicas. Para mais detalhes ver Michael (1996). Sobre a preferência da sociologia da translação pelo termo coletivo em vez do termo social, ver Latour (2001).
} 
modernista: Ciência e tecnologia permitem que a mente rompa com a sociedade para alcançar a natureza objetiva e impor ordem à matéria eficiente.

Mudar o quadro de referência social seria uma necessidade de compreender que há simetria entre os humanos e os objetos, algo não cogitado pelos cientistas sociais quando ignoraram o importante papel destes últimos em suas análises acerca da realidade.

A ideia é que a sociedade é feita de humanos e não humanos, sujeitos e objetos. No cotidiano, humanos e não humanos nunca estão dissociados. Eles formam, em conjunto, redes que constituem aquilo que chamamos de real. Cada ação que realizamos está associada, ou é mediada, por não humanos que também agem, apresentado, assim como os humanos, capacidade de ação (PECl e ALCADIPANI, 2006, p. 148).

O processo de construção é coletivo, ou seja, tudo se constrói desse modo, inclusive os fatos. Para que isso seja possível é necessária a mobilização de uma diversidade de elementos heterogêneos. É justamente na heterogeneidade de associações que está o envolvimento de humanos e não humanos (PECI e ALCADIPANI, 2006). Em torno de uma fabricação (termo sinônimo de construção muito usado por LATOUR, 2000; 2001) juntam-se artefatos, técnica, interesses, ciência, computadores, conhecimento, história e pessoas, entre outros elementos impossíveis de ser totalmente percebidos na sua completude. Latour (2001) não considera que o processo de fabricação seja um jogo no qual a soma dos elementos isolados é sempre igual à soma das partes quando estas são associadas. Os elementos introduzidos nunca saem do processo com as mesmas propriedades e características iniciais; eles se transformam e também são transformados.

Conforme afirmam Peci e Alcadipani (2006), o vocabulário relacionado ao processo de fazer enfatiza o papel de alguma agência. Entretanto, quando nos tornamos atentos e humildes observadores, essa agência se desloca de um mestre todo-poderoso para as diversas coisas com as quais temos de dividir a ação. Humanos e não humanos passam a ser considerados simétricos, assim como a ação passa a ser considerada distribuída entre as diversas entidades que a constituem.

\section{O PROGRAMA FORTE DE SOCIOLOGIA DO CONHECIMENTO}

Antes mesmo de a TAR adquirir esse nome, o trabalho seminal de Latour e Woolgar (1997), lançado em 1979, introduziu diversos conceitos fundamentais para o desenvolvimento teórico que viria, incluindo o conceito de simetria. $\mathrm{O}$ conceito de simetria derivado do Programa Forte de Sociologia do Conhecimento (PFSC) possibilitou elaborar o argumento de um mesmo estatuto ontológico entre discursividade e materialidade, humanidade e objetividade. Entretanto, o uso do conceito de simetria não é originário de Latour e Woolgar (1997), mas, sim, do PFSC (BLOOR, 1976). Essa influência contribuiu para distinguir a TAR de outras correntes teóricas. Por meio de preocupações relacionadas com a criação, a estabilização, a transmissão e a manutenção de conhecimento, Bloor (1976) exemplifica algumas das principais questões dos sociólogos desse campo. A sociologia do conhecimento ofereceu abordagens inovadoras. Em sua época, Bloor (1976) identificou que todas as abordagens anteriores lidavam com os processos sociais internos (relacionados com a visão internalista da ciência e da tecnologia) e não com questões atribuídas às influências externas sofridas, por exemplo, pelo processo de demarcação de um campo específico de conhecimento científico. Bloor (1976) critica, por exemplo, a metodologia dos programas de pesquisa (LAKATOS, 1979) por conta do enfoque na capacidade relativamente autônoma das disciplinas científicas para se consolidar a despeito de todo tipo de influência externa proveniente de uma infinidade de contingências.

Partindo dessas considerações, Bloor (1976) apresenta quatro dogmas que deveriam orientar o PFSC: causalidade, imparcialidade, simetria e reflexividade. O primeiro considera que as condições pelas quais crenças e conhecimentos são criados são causais. O segundo pressupõe imparcialidade entre verdade e falsidade, racionalidade e irracionalidade, sucesso e falha. Ambos os lados dessas dicotomias devem ser explicados e não apenas aqueles ligados aos aspectos socialmente considerados não verdadeiros, como a irracionalidade e o insucesso. O terceiro considera que o estilo da explicação deve ser simétrico. A mesma causa explicaria, por exemplo, crenças verdadeiras e falsas. O quarto refere-se à reflexividade, ou seja, em princípio, os padrões de explicação do PFSC deveriam ser aplicáveis à sociologia em si, e vice-versa. 
Dois dogmas dos PFSC exerceram grande influência epistemológica sobre a TAR. São eles os princípios de imparcialidade e de simetria. Latour e Woolgar (1997) e Latour (1996) produzem uma série de evidências empíricas para o PFSC, as quais avançaram para além das pressuposições de David Bloor. Por meio da imparcialidade e da simetria, Latour e Woolgar (1997) entendem que não seria suficiente, na compreensão do desenvolvimento das ciências, o cerceamento de sua dimensão cognitiva a alguns poucos fatores sociais. Seria necessário, ao contrário, penetrar no âmbito mais profundo em que a produção científica estava inserida, considerando iguais em importância tanto a sua dimensão social quanto a sua dimensão científica.

Para Bloor (1976) e Latour e Woolgar (1997), toda a explicação acerca do desenvolvimento científico deve ser simétrica. Fora do PFSC, dimensões sociais, psicológicas e econômicas (entre outras) só entram na análise quando algo dá errado. Por exemplo, para explicar o porquê de os franceses acreditarem em astrologia, uma vez que a astrologia não tem evidências científicas. Para isso, todo o tipo de explicação extracientífica pode ser razoável, a fim de compreender tal manifestação ilógica e aparentemente sem sentido. Entretanto, não se buscam explicações em dimensões sociais, psicológicas etc. para entender o porquê de os franceses acreditarem em astronomia. Afinal, acreditar em astronomia seria algo plenamente lógico e pleno de sentido (LATOUR e WOOLGAR, 1997). Considerar que o que dá certo, do ponto de vista lógico, não necessita de explicação fora da dimensão cognitiva da ciência é comportar-se de modo assimétrico. Latour e Woolgar (1997) rompem definitivamente com esse tipo de filosofia da ciência.

Entretanto, diferentemente de Bloor (1976) (e sob protestos dele), Latour e Woolgar (1997) avançam em relação aos pressupostos preestabelecidos acerca do conceito de simetria. Marques (2006a) afirma que, especialmente no plano ontológico, a noção de simetria de Latour e Woolgar (1997) é distinta. Ela não se refere apenas ao tratamento equânime, relevante e suficiente entre vencidos e vencedores da história das ciências. O tipo de simetria generalizada de Latour estimula a considerar sociedade e natureza constituintes do mesmo plano ontológico (LATOUR, 2005a). Se, de modo assimétrico, é presumível considerar que apenas pessoas podem ser agentes e performar o mundo, por meio da noção generalizada de simetria introduzida por Latour e Woolgar (1997), humanos e não humanos são equânimes e cúmplices na geração de agenciamentos e performatividades (MARQUES, 2006a). Essa mesma concepção de simetria também foi incorporada por Callon (1986), o qual procurou explicar não apenas os pontos de vista conflituosos e os argumentos contraditórios da ciência e da tecnologia, mas sociedade e natureza em um mesmo plano simétrico.

A partir da simetria generalizada é possível entender um pressuposto fundamental da TAR, relacionado com a recusa em perceber o mundo por meio de divisões entre polos distintos com qualidades intrínsecas. A simetria permite perceber que o mundo, a realidade e todas as entidades atuantes são produto de relações, fabricações e construções intermináveis, em que o objetivo e o subjetivo se misturam e se transformam. Cada entidade (por exemplo, um ministro de Estado, a pesquisa espacial, uma rede social, um computador ou a própria TAR) é marcada por um atributo imprescindível: o hibridismo entre humanos e não humanos. Não há como isolar características de um ou de outro.

\section{O PROCESSO DE TRANSLAÇÃo}

Assim como a simetria, outros conceitos foram trazidos e incorporados pela TAR. Desses, o de translação tornou-se uma categoria-chave. Ele é tão importante que a própria TAR também é chamada de "sociologia da translação" (CZARNIAWSKA, 2009). No cerne dessa questão está a inspiração do pensamento filosófico de Michel Serres. A influência de Serres sobre Latour é extensa ${ }^{5}$. A crítica da modernidade baseada na impossibilidade prática do homem de separar (purificar) as ciências do mundo exterior (separar o fato da crença) é muito influenciada por Michel Serres. A antropologia das ciências praticada por Bruno Latour foi primeiro praticada por Michel Serres e exprime a noção original de imbricação entre cultura e prática 
científica, algo revolucionário para epistemólogos como Bachelard, o qual pregava a ruptura entre ciências e humanidades e o progresso científico pela filosofia do não ${ }^{6}$.

Outro exemplo dessa influência está na abordagem de Serres (1996) sobre o tempo. Partindo de intuição decorrente da teoria matemática dos números, Serres (1996) afirma que o tempo é o espaço da simultaneidade. Na teoria dos números, é possível reordenar a sequência lógica natural, de forma que os vizinhos naturais se tornam muito distantes enquanto, inversamente, números distantes se aproximam. Quando isso é aplicado à noção de tempo, por exemplo, é difícil imaginá-lo como uma linha, seja essa reta, ou entrecortada. O passado não está tão distante, esquecido ou ultrapassado. É apenas pretensa a noção de que a racionalidade do presente favorecida pela ciência moderna rompa com os mitos e os outros elementos não racionais e distantes do passado.

Sobre tal entendimento do tempo, Serres (1996, p. 83) afirma que:

O tempo não corre sempre como uma linha [...], nem segundo um plano, mas de acordo com uma variedade extraordinariamente complexa, como se aparentasse pontos de paragem, rupturas, poços, chaminés de aceleração espantosa, brechas, lacunas, tudo semeado aleatoriamente, pelo menos numa desordem visível. [...] Não é muito difícil, quando se compreendeu isso, aceitar que o tempo não se desenvolve sempre segundo uma linha: que podem, portanto, existir na cultura certas coisas que a linha fazia parecer muito afastadas e que estão de facto muito próximas, ou coisas, pelo contrário, muito próximas que, na verdade, estão distantes.

Algumas metáforas auxiliam na compreensão dessas ideias. Uma delas é a do automóvel. Um modelo recente constitui um agregado heterogêneo de soluções científicas e técnicas de diversas épocas. É possível datar peça por peça: esta inventada no início do século; já aquela, há dez anos. O ciclo de Carnot tem quase duzentos anos. A roda, por sua vez, remonta ao Neolítico. Em suma, o conjunto não é contemporâneo a não ser pela sua montagem, desenho, carroceria ou talvez pela pretensão da publicidade. "Qualquer acontecimento histórico é, desse modo, multitemporal, remete para o passado, o contemporâneo e o futuro simultaneamente" (SERRES, 1996, p. 86, grifo do original).

Outra metáfora é a do lenço. Se ele for estendido para ser passado a ferro, será possível definir sobre ele distâncias e proximidades fixas. Entretanto, se, em seguida, for dobrado, amassado e enfiado no bolso, dois pontos que antes estavam muito afastados subitamente se encontrarão muito próximos, talvez sobrepostos. Se, além disso, o lenço for rasgado em determinados lugares, dois pontos muito próximos podem ficar muito afastados. O lenço liso remete à geometria do tempo clássico. O lenço amassado, dobrado e rasgado remete à topologia do tempo experimentado, tanto no sentido íntimo quanto no exterior, na natureza. Tanto o tempo da história como o do clima. O tempo assemelha-se muito mais a essa variedade amarrotada do que à lisa, demasiadamente simplificada (SERRES, 1996). Como afirma Serres (1996, p. 81), "cada invenção desvenda ao mesmo tempo o real e o histórico".

Cabe aos processos de translação produzir a conexão de elementos que fabricam a realidade. Por meio de cadeias de translação, o arcaico recai sobre os ombros da atualidade, reunindo artefatos, cultura, técnica, diversos interesses, pessoas etc. Todos são trazidos à tona. A translação em Michel Serres aparece em sua obra Hermes (SERRES, 1990) como um processo de construir conexões, forjar passagens entre domínios ou, simplesmente, estabelecer comunicação. Trata-se, no dizer do próprio Serres (1996), de um ato de invenção ou de bricolagem que emerge da mistura de elementos heterogêneos do passado, do presente e do futuro, simultaneamente.

Michel Serres considera a translação uma operação generalizada, não meramente linguística, que assume muitas formas distintas. Pode envolver o ato de deslocar ou o ato de substituir alguma coisa. Sempre envolve transformação. Consequentemente, o que é envolvido em uma translação - seja conhecimento, pessoas ou coisas - sempre assume uma identidade incerta. Cada ato de translação transforma o que translada como também aquilo que é transladado (CZARNIAWSKA, 2009). Serres (1996), assim, inverte a lógica da comunicação voltada para a transmissão e marcada pela fidedignidade.

\footnotetext{
${ }^{6}$ Gaston Bachelard (1884-1962) propõe uma visão da ciência segundo a qual esta não é concebida como um corpo de verdades que cresce gradualmente, mas como um diálogo ativo entre a razão e a experiência, no qual os fatos científicos acabam por ser tanto uma criação da mente racional quanto uma das suas descobertas. A filosofia do não contém sua concepção de progresso científico e tem afinidades com o falsificacionismo de Popper, pelo menos na possibilidade que abre para o abandono de pressuposições anteriores diante de experiências recalcitrantes que apontam para essa direção (BLACKBURN, 1997).
} 
Segundo Czarniawska (2009), o conceito de translação é útil porque é polissêmico: usualmente associado à linguagem, também medeia qualquer outro tipo de transformação e de transferência. A translação atrai interesse pelo fato de considerar a impossibilidade de uma coisa ser movida de um lugar para o outro sem que ela própria não seja transformada. Assim, a translação evoca tanto associações simbólicas quanto uma insistente materialidade. Ideias podem ser materializadas, assim como símbolos podem ser inscritos na mente das pessoas. Uma prática não estabilizada por uma tecnologia, mesmo sendo tecnologia linguística, não pode durar; é limitada por ser efêmera. Qualquer prática deve ser simplificada e abstraída em torno de uma ideia ou, pelo menos, aproximada de uma narrativa que permite uma experiência convertida em palavras ou imagens. Entretanto, para viajar no tempo e no espaço, palavras ou imagens precisam ser materializadas, corporificadas, objetivadas (CZARNIAWSKA, 2009).

Bruno Latour, John Law e Michel Callon incorporam essa noção de translação. Para Latour (2001, p. 356), de modo geral, as translações que ocorrem nas ações coletivas e representam:

[...] todos os deslocamentos por entre outros atores cuja mediação é indispensável à ocorrência de qualquer ação. Em lugar de uma rígida oposição entre contexto e conteúdo, as cadeias de translação referem-se ao trabalho graças ao qual os atores modificam, deslocam e transladam seus vários e contraditórios interesses.

Como indica Latour (2000), a expressão latina inter-esse expressa a ideia de que ele existe entre os atores de todos os tipos e os seus objetivos. Isso cria uma tensão que faz os atores selecionarem apenas o que, considerando suas limitações, os ajuda a alcançar seus objetivos entre uma multiplicidade de possibilidades existentes.

Enfocando o lado voltado para a compreensão das relações que se estabelecem entre os atores, Latour (2000) apresenta alguns exemplos de situações em que há translação de interesses. A translação, assim vista, pode ocorrer: i) quando alguém encontra e se associa a outras pessoas que querem a mesma coisa que ela: "Eu quero o que você quer"; ii) quando certa mobilização desperta interesses comuns em outras pessoas: “Eu quero; por que você não quer?" iii) quando, às vezes, para ser necessário alcançar um objetivo comum, alguém tem de ceder e se desviar um pouco de seu objetivo inicial: "Se você desviasse um pouquinho..."; iv) quando há remanejamento de todos os interesses e os objetivos iniciais: deslocar objetivos; inventar novos objetivos; inventar novos grupos; tornar invisível o desvio; vencer as provas de atribuição (rejeitando a tendência dos historiadores ou, mesmo, dos próprios atores, em atribuir maior ou menor responsabilidade pela invenção a um ou a outro ator); e v) quando todos os agentes passam a se mobilizar em torno de uma ação coletiva de modo voluntário, contribuindo para a propagação de uma tese no tempo e no espaço: tornar-se indispensável7.

Para Callon (1986), translação é transformação. Os processos de translação são os momentos por meio dos quais a identidade dos atores, a possibilidade de interação e as margens de manobra são negociadas e delimitadas.

Law (2003) vai além ao comparar translação à traição. Para o autor, tradução remete a similaridade, fidedignidade entre a origem e o resultado daquilo que é traduzido. Traição, ao contrário, remete à diferença que transforma. Para exemplificar, o autor questiona a possibilidade de haver transferência de tecnologia. Isso porque, de modo geral, entende-se que, para haver transferência de tecnologias, há também o pressuposto de que elas são passadas de uma mão à outra de maneira simplista, sem que atravessem um processo de transformação. Ao se considerar que tecnologias têm qualidades intrínsecas, elas também são performativas, uma vez que, quando mudam de mão, também precisam ser ressignificadas e reelaboradas. Para Law (2003), a translação visa a minar a ideia de que poderia haver algo como fidelidade de representação: tradução fiel. Isso implica destacar a afirmação de que todas as representações também traem seu objeto ${ }^{8}$. Não pode existir, assim, algo como transferência de tecnologia. Não no sentido que a princípio se atribui, que considera que a tecnologia se origina em um ponto e depois se espalha. Em vez disso, ela passa de mão a mão e, à medida que ela passa, muda. É transformada. Torna-se menos e menos reconhecível (LAW, 2003).

\footnotetext{
${ }^{7}$ Imagine a possibilidade de ver uma tese logo se transformar em uma caixa-preta comum nas mãos de todos. "Os contendores simplesmente se sentariam em seus lugares e os outros passariam sem esforço por entre eles adotando suas teses, comprando seus produtos, participando de bom grado da construção e da disseminação de caixas-pretas" (LATOUR, 2000, p. 198).

${ }^{8}$ Law (2003) inclui aqui a própria representação da TAR e assume que seria incoerente esperar construir por meio dessa um conjunto de pressupostos fundamentais, uma vez que a própria TAR está sujeita a transformação quando muda de mãos.
} 


\section{ATUAÇÃO NÃO HUMANA}

Como pensar na figura do ator dissociada da noção de atuação apenas humana? A atuação dos não humanos é uma das características mais marcantes da TAR, mas também uma das mais complexas e pouco compreendidas. Uma influência importante para resolver essa problemática veio dos estudos semiológicos do lituano de origem russa Algirdas Greimas (1917-1992). Segundo Czarniawska (2009), Greimas introduziu a noção de atuantes como sujeitos gramaticais, os quais podem ou não se revelar como pessoas. Um atuante é aquele que faz ou sofre um ato. Isso inclui não apenas seres humanos, mas também animais, objetos e conceitos. A substituição da palavra ator tem sido feita para mostrar que os atuantes mudam de papéis ao longo de uma narrativa. $\mathrm{O}$ atuante pode adquirir o caráter de ator ou pode continuar sendo objeto da ação de algum ator. As ideias da semiótica de Greimas permitiram a elevação de associações entre atuantes e artefatos físicos a um papel mais relevante. Enquanto o ator e a ação claramente assumem um caráter humano de conduta intencional, o atuante poderia melhor descrever a construção de macroatores, como as corporações, as sociedades e as instituições (CZARNIAWSKA, 2009).

Assim, um sumário dos procedimentos de pesquisa guiados pela TAR implicaria a identificação de atuantes e persegui-los por meio de uma trajetória determinada por uma série de programas e antiprogramas de ação, até que, enfim, esses atuantes se tornem atores, adquirindo um caráter relativamente distinto e estável. Quais atuantes se tornam atores? Aqueles ligados a programas que têm sucesso em combater antiprogramas ou, alternativamente, aqueles que estão ligados a antiprogramas que vencem os programas, como nas histórias de oposição e de resistência (CZARNIAWSKA, 2009).

Essa virada semântica que faz repensar e reconstruir o próprio significado do ator de agente pessoa para uma estrutura mais ampla e complexa que mobiliza e é mobilizada por elementos heterogêneos produzindo ou deduzindo de programas de ação cria uma abordagem original para considerar a criação das entidades performáticas. Um exemplo dessa possibilidade de ação produzida no espaço exterior à pessoa está nos estudos de Hutchins (1995).

Conforme explica Hutchins (1995), há dois episódios importantes no desenvolvimento do campo da antropologia. O primeiro está relacionado ao entendimento de que o conhecimento é puramente um fenômeno intrínseco do indivíduo. A questão fundamental nesse escopo é: O que faz uma pessoa conhecer? O lócus do conhecimento é assumido como pertencente ao espaço interior do indivíduo, sendo os métodos de pesquisa baseados na formação de conhecimento a partir da linguagem.

O segundo episódio foi marcado pela redefinição do foco que saiu da linguagem e foi para o estudo da prática das pessoas. Os antropólogos passaram a considerar duas coisas: Como as pessoas conhecem o que conhecem e qual contribuição os ambientes provocam na assimilação de conhecimento? Hutchins (1995) sugere que tais pressupostos privilegiaram a ênfase em descobrir e descrever estruturas de conhecimento que estão em algum lugar dentro do indivíduo. Ao observar a prática, por exemplo, de conducentes de navios da marinha e de pilotos de avião, Hutchins (1995) introduziu a ideia de que a cognição humana está também situada em um complexo mundo externo do qual não pode se desvincular. $O$ conceito de cognição distribuída procura justamente desenvolver a ideia de cognição como uma espécie de ecologia de pensamento que sintetiza a interação humana com os recursos acessíveis e dispersos do ambiente (HUTCHINS, 1995). Esse exemplo da psicologia auxilia a compreender a natureza da ação e o motivo pelo qual essa não possa ser restringida a espaços delimitados. Conforme afirma Latour (2005a), o problema não está em localizar a origem da ação, uma vez que essa tarefa é um tanto impossível, pois a ação está dispersa no espaço e no tempo em meio ao movimento de uma infinidade de entidades e movimentos sobrepostos. $\mathrm{O}$ ator, como apresentado nos aspectos fundamentais que definem a TAR, só é ator na rede de elementos humanos e não humanos que o sustenta. Conforme mudam as associações estabelecidas entre ele e a rede, mudam também sua identidade e os efeitos que ele produz sobre a realidade. Assim como a cognição para Hutchins (1995), a ação na perspectiva da TAR é distribuída (LATOUR, 2005a). A esse respeito comenta Latour (2001, p. 324): "Quem jamais dominou uma ação? Mostrem-me um romancista, um pintor, um arquiteto, um cozinheiro que não tenha, como Deus, sido surpreendido, arrebatado por aquilo que ela [...] já não estava fazendo".

Desse modo, a ação pode ser sugestiva, influenciada, traída, transladada e emprestada (LATOUR, 2005a). Uma característica fundamental, em se tratando do uso da expressão "ação distribuída" (entre elementos heterogêneos humanos e não humanos) está na surpresa acerca de seus desdobramentos, mesmo quando se é expectante de domínio completo do que se faz. 


\section{CONSIDERAÇÕES FINAIS}

Ao sintetizar algumas origens e afiliações epistemológicas da TAR foi possível apresentar conceitos e abordagens que servem a uma compreensão mais aprofundada dessa perspectiva que adquire cada vez mais adeptos no contexto da análise organizacional e da administração. O esforço é relevante, uma vez que se percebe um crescente interesse da comunidade acadêmica por orientações teóricas que fogem ao mainstream funcionalista que tem influenciado e moldado o campo de pesquisa em administração desde Taylor e Fayol. Segundo Serva, Dias e Alperstedt (2010), estudos que procuram sedimentar paradigmas emergentes podem auxiliar na redução de dificuldades epistemológicas da teoria das organizações.

Algumas implicações desse esforço podem ser úteis. A primeira resume-se nas possibilidades para a inserção de categorias dos estudos de ciência e tecnologia na análise organizacional. Acredita-se que elas podem ser úteis para compreender variados temas de interesse, como a mudança organizacional e os processos de motivação e de empreendedorismo. Os conceitos estudados, por exemplo, permitem conciliar diferentes disciplinas, como sociologia e filosofia da ciência, em uma abordagem interdisciplinar que apresenta afinidade com os estudos organizacionais. É possível ampliar o referencial explicativo, por exemplo, para os processos de mudança entendidos como mecanismos de mobilização de estruturas tecnológicas diferentes, definidas por limites de especializações técnicas ou por ambientes e realidades distintos.

A segunda se dá por meio de uma análise crítica reflexiva entre a abordagem construtivista e o conceito de simetria. Não são comuns reflexões sobre os pressupostos introduzidos por meio do conceito de simetria. Entretanto, acredita-se que a compreensão ampliada de sua origem auxilia no entendimento do que distancia construtivismo social e construtivismo crítico. Perceber o papel exercido pelos atores constituídos simultânea e simetricamente de pessoas e de coisas, adotando para isso uma abordagem metodológica que procura identificá-los e persegui-los, torna-se fundamental para compreender como a realidade é fabricada, inclusive o próprio processo organizativo. O conceito de simetria também oferece um relevante argumento contra o paradigma internalista de história da ciência que alimenta, inclusive, o funcionalismo na administração. Segundo Marques (2006b), quando se considera o contexto social onde qualquer ciência está inserida, abrem-se mais possibilidades para uma correta interpretação do conhecimento científico. Dessa forma, a própria ciência da administração deixa de ser neutra e passa a ser percebida como um complexo sistema de crenças, valores, limites e possibilidades.

Uma última implicação destacada tem relação com as novas possibilidades que a noção de translação abre para a análise organizacional. Para entender o processo organizativo é necessário compreender como a ação pode ser distribuída em meio a uma infinidade de atores e atuantes. Os processos de translação ocupam um papel importante, pois são os mecanismos de ligação entre pessoas e coisas que permitem, por exemplo, a transformação de atuantes em atores, assim como o estabelecimento de programas ou antiprogramas performáticos de ação distribuída. Por meio dos processos de translação é possível criar entidades reais da disjunção caótica de elementos, gerando conjunção por meio de conexões improváveis. Quando se estabilizam no contexto organizacional, elas se tornam, por exemplo, rotinas, tecnologias ou princípios, os quais escondem os diversos elementos heterogêneos que se associam na sua fabricação. Mesmo que haja apropriação do conceito de translação de modo coerente, ainda assim a imersão mais aprofundada em suas origens na filosofia matemática de Michel Serres e a noção de tempo topográfico incorporam elementos adicionais para compreendê-lo mais amplamente, colaborando para a sedimentação do uso da TAR e de suas categorias principais na análise organizacional.

O desafio que se coloca diante dos estudos organizacionais e da ciência administrativa como um todo não é simples. Como afirma Serva, Dias e Alperstedt (2010), ao mesmo tempo que há a necessidade de proporcionar uma leitura mais profunda e complexa do fenômeno organizacional, a grande maioria dos estudos ainda se atém a métodos tradicionais de orientação funcionalista. Caminhar na direção de resolver esse dilema significa também intensificar esforços rumo a discussões essenciais de cunho epistemológico. O esforço desse artigo ressalta a importância de pequenas, mas importantes contribuições que possam ser úteis àqueles que não se conformam com o trivial e buscam orientar suas pesquisas por abordagens que se colocam em uma posição crítica em relação ao funcionalismo e ao positivismo, como é o caso da TAR. 


\section{REFERÊNCIAS}

AKRICH, M.; LATOUR, B. A summary of a convenient vocabulary for the semiotics of human and nonhuman assemblies. In: BIJKER, W.; LAW, J. (Eds.). Shapping technology, building society: studies in sociotechnical change. Cambridge, MA: TheMIT Press, 1992. 259-264 p.

ALCADIPANI, R.; HASSARD, J. Actor-Network Theory, organizations and critique: towards a politics of organizing. Organization, v. 17, n. 4, p. 419-435, 2010.

ALCADIPANI, R.; TURETA, C. Teoria Ator-Rede e análise organizacional: contribuições e possibilidades de pesquisa no Brasil. Organizações \& Sociedade, v. 16, n. 51, p. 647-664, 2009.

BERGER, P. L.; LUCKMANN, T. A construção social da realidade: tratado de sociologia do conhecimento. Rio de Janeiro: Vozes, 2008.

BIJKER, W. E. Of bicycles, bakelites, and bulbs: toward a theory of sociotechnical change. Cambridge, MA: The MIT Press, 1995.

BIJKER, W. E.; LAW, J.; Shaping technology/building society: studies in sociotechnical change. Cambridge, MA: The MIT Press, 1992.

BLACKBURN, S. Dicionário Oxford de filosofia. Rio de Janeiro: Jorge Zahar, 1997.

BLOOR, D. Knowledge and social imagery. London: Routledge \& Kegan Paul, 1976.

CALLON, M. Some elements of a sociology of translation: domestication of the scallops and the fishermen of St Brieuc Bay. In: LAW, J. (Ed.). Power, action and belief: a new sociology of knowledge? London: Routledge, 1986. 196-223 p.

CALLON, M. Actor-network theory: the market test. In: LAW, J.; HASSARD, J. (Eds.). Actor-Network Theory and after. London: Blackwell, 1999. 181-195 p.

CAMARGO-BORGES, C.; RASERA, E. F. Social constructionism in the context of organization development. SAGE Open, v. 3, n. 2, p. 1-7, 2013.

CAVALCANTI, M. F. R.; ALCADIPANI, R. Organizações como processos e Teoria Ator-Rede: a contribuição de John Law para os estudos organizacionais. Cad. EBAPE.BR, v. 11, n. 4, p. 556556, 2013.

COWAN, D.; CARR, H. Actor-network theory, implementation, and the private landlord. Journal of Law and Society, v. 35, n. 1, p. 149-166, 2008.

CZARNIAWSKA, B. Emerging institutions: pyramids or anthills? Organization Studies, v. 30, n. 4, p. 423-441, 2009.

CZARNIAWSKA, B.; HERNES, T. Actor-Network Theory and organizing. [S.I]: Liber, 2005.

DAVENPORT, E. Actor-network theory and organizing. Management Learning, v. 37, n. 2, p. 248-250, 2006.

GEELS, F., W. Technological transitions and system innovations: a co-evolucionary and socio-technical analysis. Cheltenham: Edgar Elgar, 2005.
GERGEN, K. J.; THATCHENKERY, T. J. Organization science as social construction. The Journal of Applied Behavioral Science, v. 40, n. 2, p. 228-249, 2004.

GIDDENS, A. A constituição da sociedade. São Paulo: Martins Fontes, 1989.

HACKING, I. The social construction of what? Cambridge, MA: Harvard University Press, 1999.

HAGENDIJK, R. Structuration theory, constructivism, and scientific change. In: COZZENS, S. E.; GIERYN, T. F. Theories of science in society. Bloomington, IN: Indiana University Press, 1990. 43-66 p.

HESS, D. J. Science and technology in a multicultural world: the cultural politics of facts and artifacts. New York: Columbia University Press, 1995.

HUGHES, T. P. The seamless web: technology, sience, etcetera, etcetera. Social Studies of Science, v. 16, n. 2, p. 281-292, 1986.

HUTCHINS, E. Cognition in the wild. Cambridge, MA: The MIT Press, 1995.

KUHN, T. S. A estrutura das revoluções científicas. 9. ed. São Paulo: Perspectiva, 2006.

LAKATOS, I. O falseamento e a metodologia dos programas de pesquisa científica. In: LAKATOS, I.; MUSGRAVE, A. (Eds.). A crítica e o desenvolvimento do conhecimento. São Paulo: Cultrix, 1979. 109-243 p.

LATOUR, B. Visualisation and cognition: drawing things together. In: LYNCH, M.; WOOLGAR, S. (Eds.). Representation in scientific activity. Cambridge, MA: The MIT Press, 1990. 153-186 p.

LATOUR, B. Pasteur e Pouchet: heterogénese da história das ciências. In: SERRES, M. (Ed.). Elementos para uma história das ciências. Lisboa: Terramar, 1996. v. 3. 49-76 p.

LATOUR, B. On recalling ANT. In: LAW, J.; HASSARD, J. (Ed.). ActorNetwork Theory and after. London: Blackwell, 1999. 15-25 p.

LATOUR, B. Ciência em ação: como seguir cientistas e engenheiros sociedade afora. São Paulo: Ed. Unesp, 2000.

LATOUR, B. A esperança de Pandora: ensaios sobre a realidade dos estudos científicos. Bauro, SP: Edusc, 2001.

LATOUR, B. Políticas da natureza: como fazer ciência na democracia. Bauru, SP: Edusc, 2004.

LATOUR, B. Jamais fomos modernos: ensaios de antropologia simétrica. 3. ed. São Paulo: Ed. 34, 2005a.

LATOUR, B. Reassembling the social: an introduction to ActorNetwork-Theory. Oxford: Oxford University Press, 2005b.

LATOUR, B.; WOOLGAR, S. Vida de laboratório: a produção dos fatos científicos. Rio de Janeiro: Relume Dumará, 1997.

LAW, J. After ANT: complexity, naming and topology. In: LAW, J.; HASSARD, J. (Eds.). Actor-Network Theory and after. London: Blackwell, 1999. 1-14 p. 
LAW, J. Traduction/trahison: notes on ANT. Lancaster: Lancaster University, 2003.

MARQUES, D. B. Performatividade e agenciamentos humanos e não humanos da realidade: uma leitura por trás da lei de biossegurança a partir da sociologia simétrica de Bruno Latour. 302 f. Tese (Doutorado em Sociologia) - Universidade Federal de Pernambuco, Recife, 2006a.

MARQUES, D. B. Resenha: knowledge and social imagery. Gestão. Org, v. 4, n. 2, p. 225-226, 2006 b.

MICHAEL, M. Constructing a constructive critique of social constructionism: finding a narrative space for the non-human. New Ideas in Psychology, v. 14, n. 3, p. 209-224, 1996.

MONTENEGRO, L. M.; BULGACOV, S. Governança e estratégia de cursos de graduação em administração na perspectiva da Teoria Ator-Rede. Revista de Administração Contemporânea, v. 19, n. 2, p. 212-231, 2015.

MUÑOZ, D. E. R. et al. Liderazgo femenil en una localidad maya de Chiapas. Un examen desde las teorías del habitus y del actor-red. Estudios Sociológicos, v. 23, n. 68, p. 485-513, 2005.

MURIEL, D. Hacer sociología a través de la teoría del actor-red: de la cartografía impresionista a la suciedad de las mediaciones. Athenea Digital: Revista de Pensamiento e Investigación Social, v. 11, n. 1, p. 111-128, 2011.

ODDONE, N. Revisitando a "epistemologia social": esboço de uma ecologia sociotécnica do trabalho intelectual. Ciência da Informação, v. 36, n. 1, p. 108-123, 2007.

ORLIKOWSKI, W. J. Sociomaterial practices: exploring technology at work. Organization Studies, v. 28, p. 1435-1448, 2007.

OUTHWAITE, W.; BOTTOMORE, T. Dicionário do pensamento social do século XX. Rio de Janeiro: Jorge Zahar, 1996.

PECI, A.; ALCADIPANI, R. Demarcação científica: uma reflexão crítica. Organizações e Sociedade, v. 13, n. 36, p. 145-161, 2006.
PRYTHERCH, D. L. Urban assemblages: how Actor-Network Theory changes urban studies. Progress in Human Geography, v. 35, n. 6, p. 855-856, 2011.

QUEIROZ E MELO, M. F. A. Discutindo a aprendizagem sob a perspectiva da Teoria Ator-Rede. Educar em Revista, v. 39, p. $177-$ 190, 2011.

ROBERTS, J. M. Poststructuralism against poststructuralism: actor-network theory, organizations and economic markets. European Journal of Social Theory, v. 15, n. 1, p. 35-53, 2012.

SERRES, M. Hermes: uma filosofia das ciências. São Paulo: Graal, 1990.

SERRES, M. Diálogo sobre a ciência, a cultura e o tempo. Lisboa: Instituto Piaget, 1996.

SERVA, M.; DIAS, T.; ALPERSTEDT, G. D. Paradigma da complexidade e teoria das organizações: uma reflexão epistemológica. Revista de Administração de Empresas, v. 50, n. 3, p. 276-287, 2010.

SILVA, T. Uso e desenvolvimento de aplicativos sociais: perspectiva da teoria ator-rede. Razón y Palabra, n. 76, p. 1-14, 2011.

TELES, A.; JOIA, L. A. Infoinclusão em Piraí Digital: evidências empíricas a partir da Teoria Ator-Rede. Journal of Information Systems and Technology Management, v. 9, n. 2, p. 369-390, 2012.

TONELLI, D. F.; BRITO, M. J.; ZAMBALDE, A. L. Empreendedorismo na ótica da teoria ator-rede: explorando alternativa às perspectivas subjetivista e objetivista. Cad. EBAPE.BR, v. 9, n. Edição especial, p. 586-603, 2011.

TSALLIS, A. C.; FERREIRA, A. L.; MORAES, M. O.; ARENDT, R. J. O que nós psicólogos podemos aprender com a teoria ator-rede. Interações, n. 22, p. 57-86, 2006.

YOUNG, R. A.; COLLIN, A. Introduction: constructivism and social constructionism in the career field. Journal of Vocational Behavior, v. 64, n. 3, p. 373-388, 2004. 